ARTICLE

Received 3 Sep 2015 | Accepted 9 Mar 2016 | Published 7 Apr 2016

DOI: $10.1038 /$ ncomms11289

OPEN

\title{
Akt1-mediated Gata3 phosphorylation controls the repression of IFN $\gamma$ in memory-type Th2 cells
}

Hiroyuki Hosokawa', Tomoaki Tanaka ${ }^{2,3,4}$, Yusuke Endo ${ }^{1}$, Miki Kato ${ }^{1}$, Kenta Shinoda ${ }^{1}$, Akane Suzuki ${ }^{1}$, Shinichiro Motohashi ${ }^{5}$, Masaki Matsumoto ${ }^{6}$, Keiichi I. Nakayama ${ }^{6}$ \& Toshinori Nakayama ${ }^{1,4}$

Th2 cells produce Th2 cytokines such as IL-4, IL-5 and IL-13, but repress Th1 cytokine IFN $\gamma$. Recent studies have revealed various distinct memory-type Th2 cell subsets, one of which produces a substantial amount of IFN $\gamma$ in addition to Th2 cytokines, however it remains unclear precisely how these Th2 cells produce IFN $\gamma$. We herein show that phosphorylation of Gata3 at Ser308, Thr315 and Ser316 induces dissociation of a histone deacetylase Hdac2 from the Gata3/Chd4 repressive complex in Th2 cells. We also identify Akt1 as a Gata3-phosphorylating kinase, and the activation of Akt1 induces derepression of Tbx21 and Ifng expression in Th2 cells. Moreover, T-bet-dependent IFN $\gamma$ expression in IFN $\gamma$-producing memory Th2 cells appears to be controlled by the phosphorylation status of Gata3 in human and murine systems. Thus, this study highlights the molecular basis for posttranslational modifications of Gata3 that control the regulation of IFN $\gamma$ expression in memory Th2 cells.

\footnotetext{
${ }^{1}$ Department of Immunology, Graduate School of Medicine, Chiba University, 1-8-1 Inohana, Chuo-ku, Chiba 260-8670, Japan. ${ }^{2}$ Department of Clinical Cell Biology \& Medicine, Graduate School of Medicine, Chiba University, 1-8-1 Inohana, Chuo-ku, Chiba 260-8670, Japan. ${ }^{3}$ Division of Endocrinology and Metabolism, Graduate School of Medicine, Chiba University, 1-8-1 Inohana, Chuo-ku, Chiba 260-8670, Japan. ${ }^{4}$ AMED-CREST, AMED, 1-8-1 Inohana, Chuoku, Chiba 260-8670, Japan. ${ }^{5}$ Department of Medical Immunology, Graduate School of Medicine, Chiba University, 1-8-1 Inohana, Chuo-ku, Chiba 260-8670, Japan. ${ }^{6}$ Department of Molecular and Cellular Biology, Medical Institute of Bioregulation, Kyushu University, 3-1-1 Maidashi, Higashi-ku, Fukuoka 812-8582, Japan. Correspondence and requests for materials should be addressed to T.N. (email: tnakayama@faculty.chiba-u.jp).
} 
T he appropriate expression of master transcription factors and effector cytokines in $\mathrm{T}$ helper $(\mathrm{Th})$ cell subsets is essential for their immunoregulatory functions ${ }^{1,2}$. The Th2 cell differentiation programme possesses strong feed-forward mechanisms to maintain Th2 cell identity through the effector to memory phases ${ }^{3-5}$. Recent reports, however, have identified distinct memory-type Th2 cell subsets that produce a substantial amount of IL-5, IL-17 or IFN $\gamma$ in addition to IL-4 and IL-13 (refs 6,7). IFN $\gamma$ production from the memory Th2 cell subset is regulated by T-bet, the master transcription factor for Th1 cell differentiation, and its expression is crucial for preventing Lymphocytic choriomeningitis virus persistence and fatal immunopathology ${ }^{6}$. More recently, IFN $\gamma$ produced from memory $\mathrm{T}$ cells was shown to be essential for the mobilization and activation of innate cells and pathogen clearance ${ }^{8}$. However, the detailed molecular mechanisms underlying IFN $\gamma$ production from Gata3-expressing memory-type Th2 cells remain unclear.

Gata3 is predominantly expressed in $\mathrm{T}$ lymphocytes and required for both early $\mathrm{T}$-cell development in the thymus and functional differentiation of naive CD4 T cell into Th2 cells ${ }^{9-11}$. More recently, a critical role of Gata3 in group 2 innate lymphoid cell development and function was reported ${ }^{12}$. In peripheral CD4 T cells, IL-4-dependent activation of STAT6 induces the upregulation of Gata3 transcription ${ }^{13-15}$. In addition, the Ras-ERK MAPK cascade controls Gata3 stability through the ubiquitin/proteasome-dependent pathway ${ }^{16-18}$. A high-level expression of Gata3 is necessary and sufficient for Th2 cytokine expression in $\mathrm{CD} 4 \mathrm{~T}$ cells. Indeed, the deletion of Gata3 in peripheral CD4 $\mathrm{T}$ cells prevents their differentiation into the Th2 lineage, causing cells to differentiate towards a Th1 phenotype in the absence of polarizing cytokines ${ }^{19}$. Conversely, the introduction of Gata3 into developing Th1 cells switches their polarity to a Th2 phenotype ${ }^{20}$. Gata3 exerts at least three distinct functions by forming activating and repressive complexes: Gata3 induces differentiation of naive CD4 $\mathrm{T}$ cells into Th2 cells by induction of chromatin remodelling of the Th2 cytokine loci, facilitation of Th2 cell proliferation, and inhibition of Th1 cell differentiation via repression of Tbx21, encoding T-bet ${ }^{4,11,21,22}$. However, a molecular switch for organizing the distinct Gata3 complexes in Th2 cells has not yet been identified.

The function of transcription factors is regulated by several different posttranslational modifications, including acetylation, ubiquitination, sumoylation, methylation and phosphorylation ${ }^{23}$. Among them, phosphorylation has been suggested to affect strongly the function of GATA factors. Phosphorylation of Gatal at Ser310 and Ser26 is required for erythroid differentiation and attenuation of the colony-forming activity of erythrocytecommitted progenitors, respectively ${ }^{24,25}$. Insulin-dependent phosphorylation at Ser401 of Gata2 impairs Gata2 translocation into the nucleus and its DNA-binding activity during adipocyte differentiation ${ }^{26}$. A recent report demonstrated the phosphorylation of Gata3 at Thr156 in thymocytes and the function of this phosphorylation in ubiquitilation and degradation of Gata3 protein ${ }^{27}$. However, no definitive analysis has been reported regarding phosphorylation of Gata3 and its roles in Th2 cell differentiation and function.

We herein identified that phosphorylation at Ser308, Thr315 and Ser316 in the C-finger region of Gata3 plays a critical role in the repression of T-bet-mediated IFN $\gamma$ production from Th2 cells. Phosphorylation at these sites induces dissociation of Histone deacetylase 2 (Hdac2) from the Gata3/Chd4 repressive complex. We found that Akt1 is a Gata3 phosphorylating kinase for these residues, and activation of Akt1 induces derepression of Tbx21 and Ifng expression in Th2 cells. In both human and murine systems, IFN $\gamma$ expression in the IFN $\gamma$-producing memory-type Th2 cells appears to be regulated by the phosphorylation status of Gata3. Therefore, this study highlights the phosphorylation of Gata3 as a critical role in the repression of IFN $\gamma$ production from memory-type Th2 cells through the change in the organization of the Gata3 complex.

\section{Results}

Phosphorylation of Gata3 induces dissociation of Hdac2. We wished to identify the mechanisms by which the molecular switch for organizing activating and repressive Gata3 complexes occurs in Th2 cells. When Gata3 associates with the Chd4-NuRD repressive complex, the Gata3/Chd4-NuRD complex binds to the $T b \times 21$ locus and represses its expression in Th2 cells ${ }^{4}$. First, to determine which domains of Gata3 are important for binding to Chd4, Myc-tagged Chd4 and Flag-tagged wild type (WT) or deletion mutants of Gata3 (Fig. 1a, upper) were co-transfected into 293T cells and then pull-down assays were performed. The association with Chd4 was almost completely abrogated by the deletion of the two zinc finger domains of Gata3 (Fig. 1a), suggesting that the tandem zinc finger motifs of Gata3 are important for binding to Chd4.

Previous functional analyses showed that both the $\mathrm{N}$-terminal zinc finger and C-terminal zinc finger (C-finger) motifs of Gata3, each of which is followed by a conserved basic region, are crucial for the recognition and binding to the canonical GATA consensus motif, and that the $\mathrm{C}$-finger of Gata3 is required for the suppression of Tbx21 and Ifng expression (Fig. 1b) ${ }^{28,29}$. In similar pull-down assays performed in Fig. 1a, we found that the C-finger of Gata3 was important for the association of Hdac2, a subunit of the NuRD complex, to the Gata3 molecule (Fig. 1c). Based on the presence of Ser/Thr clusters in the linker region as well as the basic region around the tandem zinc fingers of Gata3, we hypothesized that Gata3 phosphorylation, especially in the region necessary for the interaction between Chd4 and Hdac2, may have a role in the regulation of the bifunctional activities of the Gata3/Chd4 complex. To test this idea, we performed a liquid chromatography-tandem mass spectrometry (LC-MS/MS) analysis to identify Gata3 posttranslational modifications using immunopurified Flag-Gata3 derived from the Th2 cell clone, D10G4.1 cells. We found that Ser308, Thr315 and Ser316 in the linker region and C-finger motif of Gata3 were phosphorylated concurrently in the 10 peptides that were detected in our mass spectrometry analysis (Fig. 1d). These Gata3 residues are conserved from drosophila to human (Fig. 1e) and appear to localize to the solvent exposed region of the protein according to a crystal structure analysis of the DNA-Gata3 complex from the Molecular Modeling Database (Fig. 1f) using the Cn3D software programme ${ }^{30,31}$.

To examine the role of phosphorylation at these sites, we generated point mutants of Gata3 in which the Ser/Thr residues were substituted to an unphosphorylatable Ala and phosphatemimic Asp (Gata3 S/T-3A and S/T-3D, respectively) (Fig. 2a, upper). 293T cells were co-transfected with Flag-tagged WT or mutants of Gata3, along with Myc-tagged Chd4, Hdac2 or HA-tagged p300, and the molecules associated with Gata3 were assessed. Interestingly, WT and mutant Gata 3 proteins preserved the association with Chd4 and p300, whereas the Hdac2 association was impaired in the phospho-mimicking Gata3 S/T-3D mutant (Fig. 2a-c). Next, we used an anti-phosphoGata3 (Ser308) antibody to address the functional role of Gata3 phosphorylation. Flag-tagged Gata3 and Myc-tagged Chd4 or Hdac2 were co-transfected into $293 \mathrm{~T}$ cells, and then total lysates were subjected to immunoprecipitation with anti-Flag $\mathrm{mAb}$ or anti-phospho-Gata3 Ab. Although Chd4 association was preserved (Fig. 2d, upper), Hdac2 association was strikingly decreased in the immunoprecipitates with anti-phospho-Gata3 $\mathrm{Ab}$ (Fig. 2d, lower). Moreover, to assess the levels of Gata3 
phosphorylation in Hdac2-associating Gata3 complexes, a two-step affinity purification using anti-Flag and anti-Myc mAbs was performed on total lysates of Flag-tagged Gata3 and Myc-tagged Hdac2 expressing 293T cells. Importantly, the Gata3 phosphorylation levels of Hdac2-associating Gata3 were substantially lower as compared with the phosphorylation levels of total Gata3 (Fig. 2e). These results indicate that phosphorylation of Gata3 at the C-finger region regulates the association of Hdac2.

Phospho-mimic Gata3 mutant fails to repress Ifng expression. To assess the functional role of phosphorylation at the C-finger motif in Gata3-mediated Th2 cell differentiation, we expressed WT, S/T-3A and S/T-3D mutants in differentiating Th1 cells using a retrovirus system and examined the expression of Tbx21, Ifng and Il4. Both WT Gata3 and S/T-3A mutant Gata3 induced Il4, and suppressed Tbx21 and Ifng expression, while the S/T-3D mutant was not able to induce Il4 expression or repress $T b \times 21$ and Ifng expression (Fig. 3a). Given that T-bet was previously shown to interact with Gata3 directly and to repress the DNA-binding activity of Gata3 (ref. 32), we next examined the ability of Gata3 mutants to induce Il4 expression using Tbx21-deficient Th1 cells to distinguish the phospho-mimic effects from the influence of T-bet-Gata3 association-dependent suppression. We found that there was no difference in the induction of Il4 among the WT, S/T-3A and S/T-3D mutants in Tbx21-deficient developing Th1 cells, suggesting that the S/T-3D mutant is capable of inducing Il4 to the same extent as WT Gata3 (Fig. 3b). In addition, the impaired repression of Ifng by the S/T-3D mutant in WT Th1 cells shown in Fig. 3a was not observed when Tbx21-deficient Th1 cells were used (Fig. 3b). These results indicate that the inability of the S/T-3D mutant to suppress IFN $\gamma$ production is likely due to its inability to repress Tbx21 expression.

We next examined the binding of Gata3 mutants to the reported Gata3-binding site (CGRE) at the Th2 cytokine loci ${ }^{33}$ and a Gata3/Chd4-binding site (G3/C4BS) at Tbx21 locus ${ }^{4}$ by ChIP assays. The binding of the Gata3 S/T-3D mutant to a

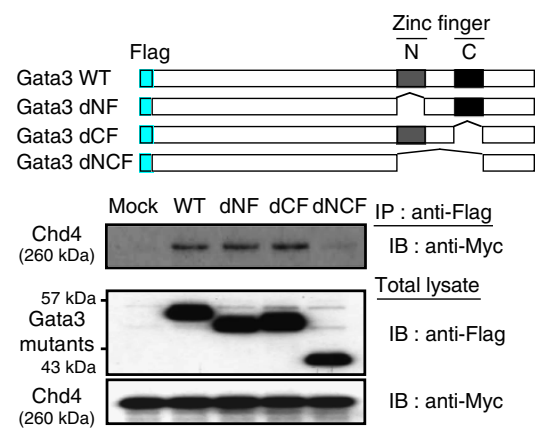

b

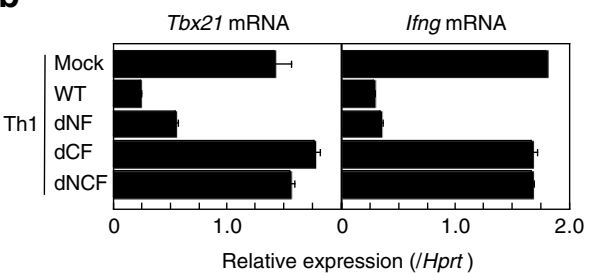

C

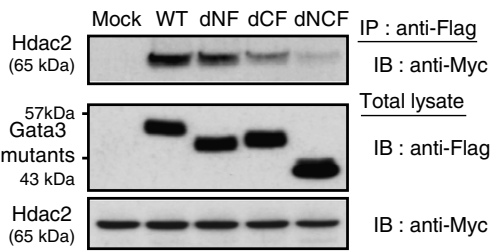

d
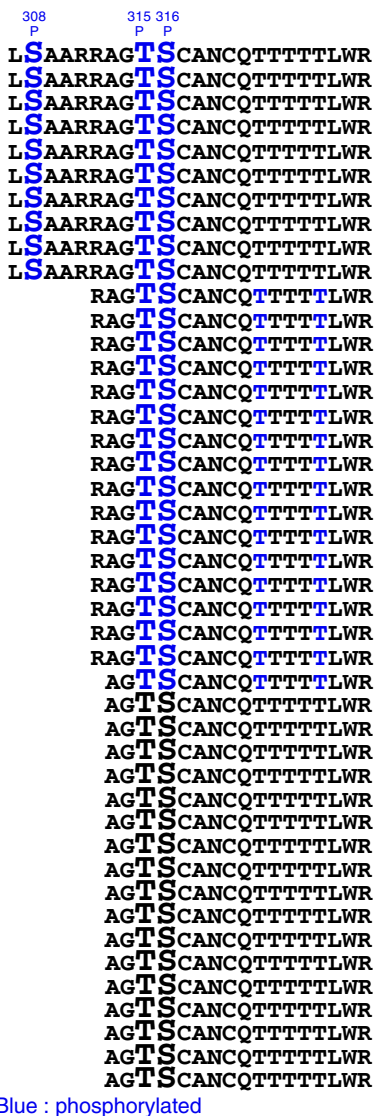

e

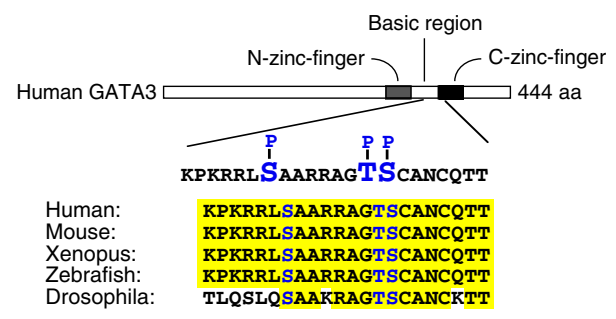

f

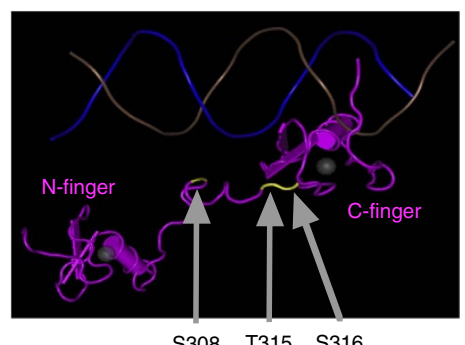

Figure 1 | Identification of Gata3 phosphorylation in the C-terminal zinc finger. (a) Schematic representations of the Flag-tagged Gata3 WT or deletion mutants are shown (top panel). Flag-tagged Gata3 WT, dNF, dCF or dNCF plasmid constructs were transfected with Myc-tagged Chd4 into $293 \mathrm{~T}$ cells. Two days later, the amount of Myc-tagged Chd4 associated with the Flag-tagged WT or mutant Gata3 was assessed by immunoprecipitation (IP) followed by immunoblotting (IB) (middle panel). Total lysates were also subjected to IB in parallel (lower panel). (b) Naive CD4 T cells were stimulated under Th1 conditions and then infected with a retrovirus vector carrying WT or mutant Gata3 cDNA. Three days later, the retrovirus-infected GFP-expressing cells were purified and the levels of mRNA of Tbx21 and Ifng were measured by RT-qPCR. The relative expression (/Hprt) is shown with s.d.'s. (c) The amount of Myc-tagged Hdac2 associated with Flag-tagged Gata3 mutants were assessed as in Fig. 1a. (d) D10G4.1 cells were infected with a lentivirus encoding Flag-Gata3 and then the immunopurified Gata3 was subjected to a LC-MS/MS analysis to assess posttranslational modifications. All Gata3 peptides including Thr315 and Ser316 detected by our mass spectrometry analysis are shown. Blue characters indicate phosphorylated amino acids. (e) The phosphorylated residues of Gata3 in the linker region of tandem zinc fingers are highly conserved from Drosophila to human. (f) The 3D structure of Gata3 zinc fingers bound to DNA, including the novel phosphorylation sites (Ser308, Thr315 and Ser316) determined using the Molecular Modeling Database $\left(\right.$ MMDB ID; 105495) ${ }^{30}$, was drawn using the Cn3D software programme. The phosphorylated Ser/Thr residues are highlighted in yellow. Four (b) and three $(\mathbf{a}, \mathbf{c})$ independent experiments were performed with similar results. 
the CGRE and Tbx21 G3/C4BS regions was significantly compromised as compared with WT or S/T-3A mutant in WT differentiating Th1 cells (Fig. 3c). To avoid the direct effect of T-bet on Gata3 repression, we performed the same ChIP assays using Tbx21-deficent Th1 cells. The binding of the Gata3 S/T-3D mutant to the CGRE region was restored to the same level of WT or S/T-3A mutant in Tbx21-deficient Th1 cells, however, the binding to the $T b \times 21$ G3/C4BS region remained significantly decreased (Fig. 3d, left). Concomitantly, p300 recruitment to the CGRE region was unaffected in S/T-3D expressing Tbx21-deficient Th1 cells (Fig. 3d, middle). Furthermore, the Hdac2 association with the Tbx21 G3/C4BS region was partially, but significantly, impaired in S/T-3D, but not in S/T-3A mutantexpressing cells (Fig. 3d, right). These results indicate that the phospho-mimic mutation of Gata3 showed decreased binding ability to the Tbx21 locus, but had no effect on the recruitment of the Gata3/p300 transcriptional activation complex to the CGRE region. Thus, the phosphorylation status of Gata3 at the $\mathrm{C}$-finger motif region appears to regulate the formation of the Gata3/Chd4-NuRD repressive complex by modulating Hdac2 association without affecting the function of the Gata3/p300 transcriptional activation complex at the CGRE region.

Identification of Akt1 as a kinase for Gata3 phosphorylation. To identify a responsible kinase for Gata3 phosphorylation,

a

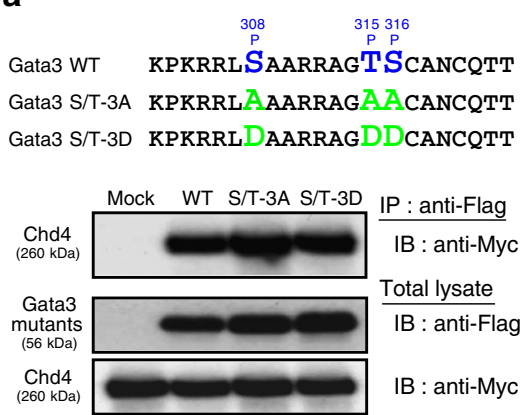

b

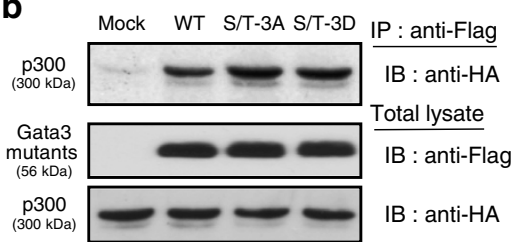

C

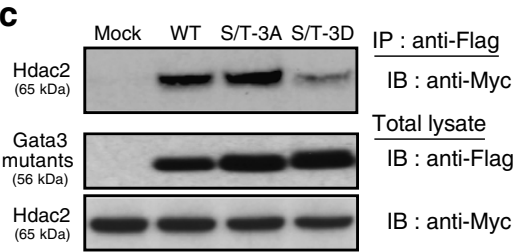

Flag-tagged Gata3 was transfected and the Gata3 complexes were immunopurified from $293 \mathrm{~T}$ cells and subjected to an in vitro kinase assay. As shown in Fig. $4 \mathrm{a}$, strong ${ }^{32} \mathrm{P}$ incorporation was detected at the molecular size of Gata3, indicating the existence of Gata3-phosphorylating kinases in Gata3-associated molecules. We next carried out an in-gel kinase assay to determine the molecular size of candidate kinases for Gata3 phosphorylation among Gata3-associated molecules. The Gata3-associated molecules were resolved on SDS-polyacrylamide gel electrophoresis (SDS-PAGE) copolymerized with GST-Gata3 protein as a substrate, and the in-gel kinase reaction was performed after denaturing and subsequent renaturing process of the proteincontaining gel as described in the Methods section. As shown in Fig. 4b, Gata3-specific kinase activity was detected at around $55 \mathrm{kDa}$ (black arrowhead), and Akt1 was identified from the 55$\mathrm{kDa}$ band by a LC-MS/MS analysis (Fig. 4b,c). These results prompted us to test physical association between Gata3 and Akt1. Flag-tagged Gata3 and Myc-tagged constitutively active Akt1 (myr-Akt1) were co-transfected into 293T cells and a complex containing Gata3 and Akt1 was detected by anti-Flag immunoprecipitation and immunoblotting with anti-Myc mAb (Fig. 4d). The levels of Gata3 phosphorylation were increased in myr-Akt1transfected 293T cells, but decreased in dominant-negative (dn) Akt1 (K179M)-transfected 293T cells (Fig. 4e). Introduction of myr-Akt1 induced the upregulation of Gata3 phosphorylation in

d
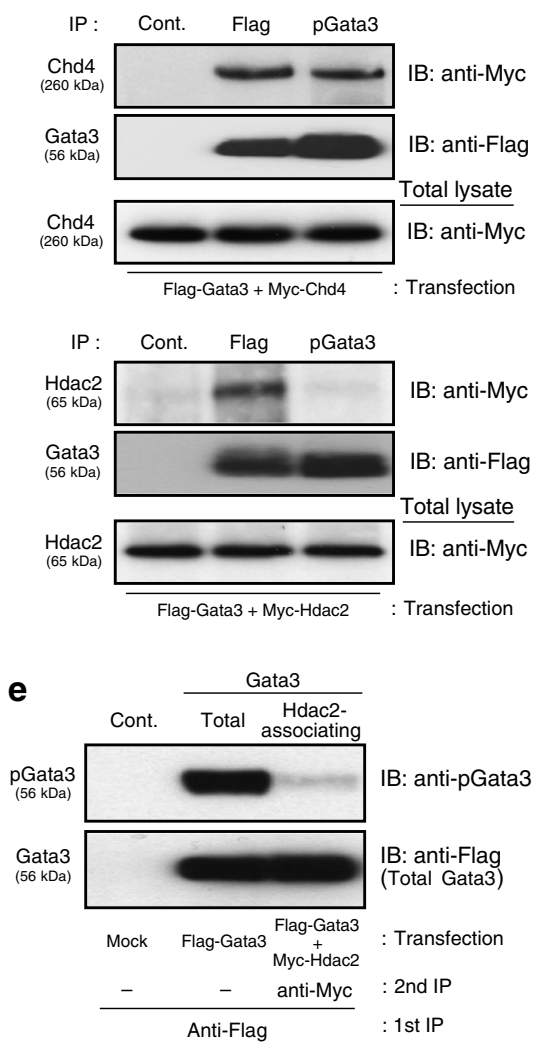

Figure 2 | Phosphorylation of Gata3 induces dissociation of Hdac2 from the Gata3 complex. (a) Comparison of the amino-acid alignment of Gata3 around phosphorylated Ser/Thr residues between WT and mutants (Gata3 S/T-3A: phospho-impaired, S/T-3D: phospho-mimic) are shown (Top panel). The amounts of Myc-tagged Chd4 associated with Flag-tagged Gata3 mutants were assessed as in Fig. 1a. (b) The amounts of HA-tagged p300 associated with Flag-tagged Gata3 mutants were assessed. (c) The amounts of Myc-tagged Hdac2 associated with Flag-tagged Gata3 mutants were assessed. (d) Total lysates from Flag-tagged Gata3 and Myc-tagged Chd4 (upper panel) or Hdac2 (lower panel) expressing 293T cells were subjected to IP with anti-Flag mAb or anti-phospho-Gata3 Ab followed by IB with anti-Flag or anti-Myc mAb. Total lysates were also subjected to IB in parallel. (e) Total lysates from Flag-tagged Gata3 and Myc-tagged Hdac2-expressing 293T cells were subjected to an initial IP with anti-Flag mAb followed by a second IP with anti-Myc mAb. The immunopurified total Gata3 and Hdac2-associating Gata3 were subjected to IB with anti-phospho-Gata3 Ab or anti-Flag mAb. Four $(\mathbf{c})$, three $(\mathbf{a}, \mathbf{b}, \mathbf{d})$ and two $(\mathbf{e})$ independent experiments were performed with similar results. 
a

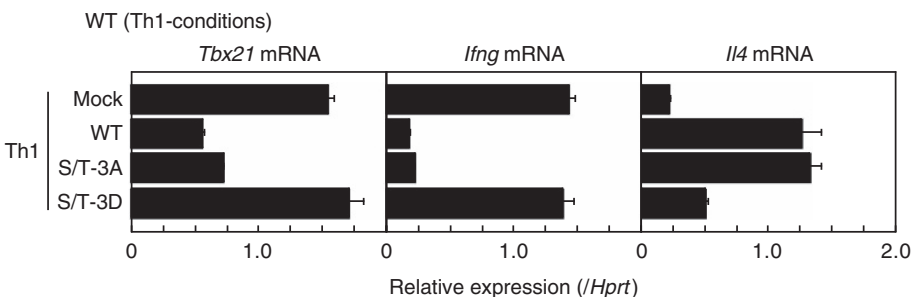

b

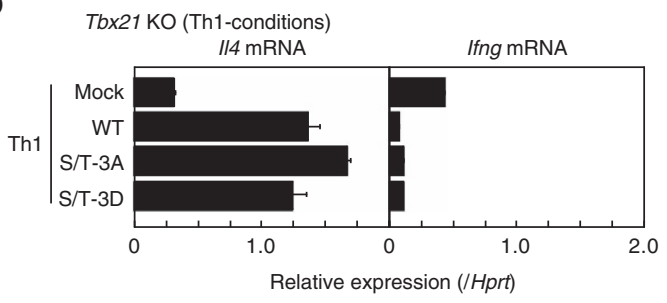

C

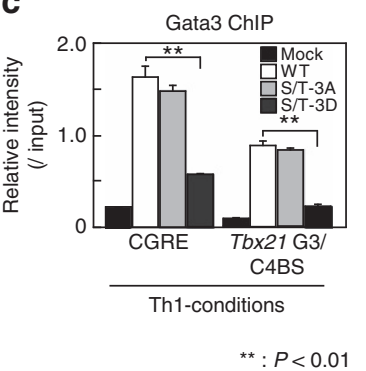

d

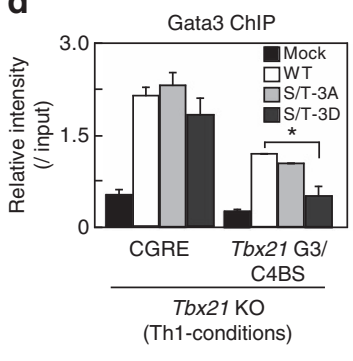

p300 ChIP

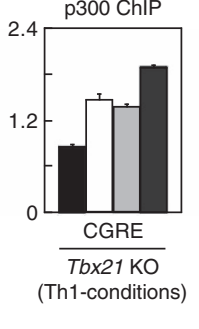

Hdac2 ChIP

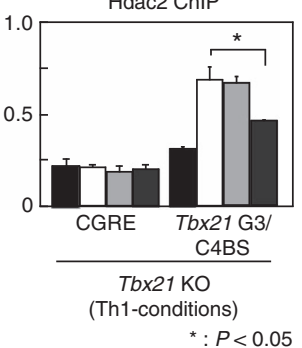

Figure 3 | Phosphorylated Gata3 is incapable of repressing T-bet-dependent Ifng expression. (a,b) Naive CD4 T cells from WT (a) or Tbx21-deficient (b) mice were stimulated under Th1 conditions and then infected with a retrovirus vector carrying WT or mutant Gata3 (S/T-3A, S/T-3D) cDNA. Three days later, the retrovirus-infected GFP-expressing cells were purified and the levels of mRNA of Tbx21 were measured by RT-qPCR (a). For the induction of cytokines, the cells were stimulated with immobilized anti-TCR $\beta$ mAb for another $4 \mathrm{~h}$ and then extracted RNA was subjected to RT-qPCR to assess I/4 and Ifng mRNA expression (a,b). (c,d) Binding of Gata3 WT and mutants (WT, S/T-3A, S/T-3D), p300 and Hdac2 at the CGRE and the Tbx21 G3/C4BS region was determined by ChIP assays followed by qPCR analyses in WT (c) or Tbx21-deficient (d) Th1 cells treated as in a,b. The mean values with s.d.'s are shown. ${ }^{\star \star} P<0.01,{ }^{\star} P<0.05$ by Student's $t$-test. Four $(\mathbf{a})$, three (b) and two $(\mathbf{c}, \mathbf{d})$ independent experiments were performed with similar results.

parallel with the phosphorylation status of Akt1 (T308) in primary Th2 cells (Fig. 4f,g). To confirm that Akt1 is a Gata3-phosphorylating kinase, purified recombinant Gata3 was incubated with immunopurified myr-Akt1 in the absence or presence of Akt inhibitor XI. Gata3 phosphorylation was easily detected by immunopurified Akt1 and its phosphorylation was suppressed by the Akt inhibitor in a dose-dependent manner (Fig. 4h,i). Taken together, these results indicate that Akt1 is one of responsible kinases for Gata3 phosphorylation.

Akt1 activation induces the derepression of IFN $\gamma$ expression. We previously reported that inhibiting the function of the Gata3/Chd4-NuRD complex by a HDAC inhibitor, trichostatin $\mathrm{A}$, induces IFN $\gamma$ production from Th2 cells ${ }^{4}$. Thus, we sought to address whether Akt1-dependent phosphorylation of Gata3 and subsequent dissociation of Hdac2 from the Gata3 complex plays a role in the IFN $\gamma$ production from Th2 cells. The active form of Akt1, myr-Akt1, was introduced into differentiating Th2 cells in vitro, and then the IFN $\gamma$ production was assessed. The percentage of IFN $\gamma$-producing cells was increased in myr-Akt1 introduced Th2 cells (20.3\% versus $37.5 \%)$, whereas no obvious effect was observed in the percentage of IL-4-producing cells (46.5\% versus 50.8\%) (Fig. 5a, left and middle). In addition, the introduction of the unphosphorylatable Gata3 S/T-3A mutant repressed the myr-Akt1-mediated upregulation of IFN $\gamma$ production in Th2 cells (Fig. 5a, right). In accordance with the induction of IFN $\gamma$ production, mRNA transcripts of Tbx21 and Ifng were increased in myr-Akt1-introduced Th2 cells and the upregulation of Tbx21 and Ifng mRNA mediated by myr-Akt1 was strongly repressed in Th2 cells in which the Gata3 S/T-3A mutant was introduced (Fig. 5b). Flag-tagged Gata3 and myrAkt1 or dominant-negative Akt1 (dn Akt1) were co-transfected into $293 \mathrm{~T}$ cells and the ability of Gata3 to associate with Myctagged Hdac2 was assessed by immunoprecipitation experiments. The levels of Hdac2 association with Gata3 were decreased in myr-Akt1-transfected cells, but not in dn Akt1-transfected cells (Fig. 5c). Moreover, the binding of Hdac2 to the Tbx21 G3/C4BS region was decreased in myr-Akt1-introduced Th2 cells (Fig. 5d). These results indicate that the activation of Akt1 regulates the dissociation of Hdac2 from the Gata3 complex and the derepression of $T b \times 21$ and Ifng expression in Th2 cells.

T-bet-dependent IFN $\gamma$ production from memory Th2 cells. Recently, distinct memory-type Th2 cell subsets have been identified in several groups, which produce a substantial amount of IL-5, IL-17 or IFN $\gamma$ in addition to IL-4 and IL-13 (ref. 7). IFN $\gamma$ expression in Th2 cells is reported to be dependent on T-bet and plays an important role in the protective immunity against viral infections $^{6}$. We examined whether Gata3 phosphorylationinduced derepression of $T b \times 21$ expression is involved in the 
a
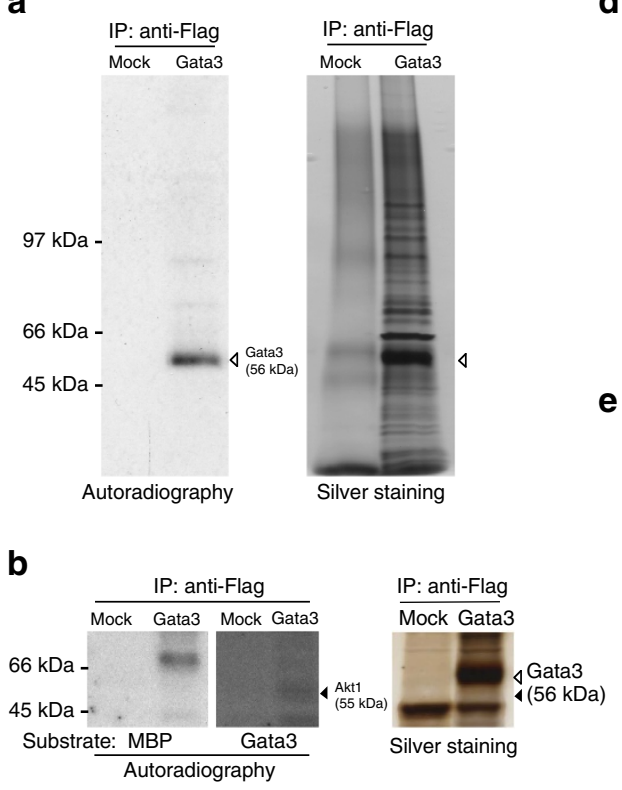

C

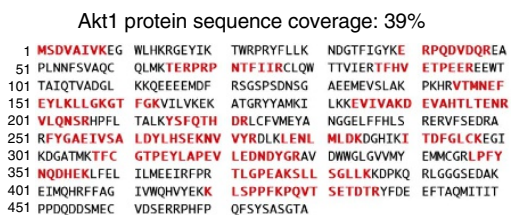

d
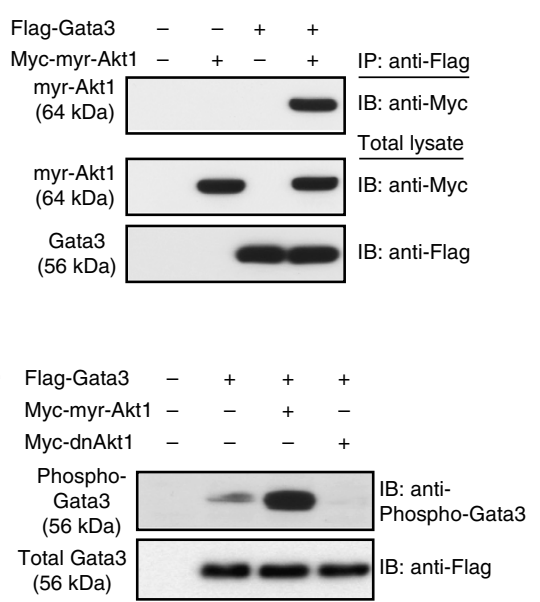

f

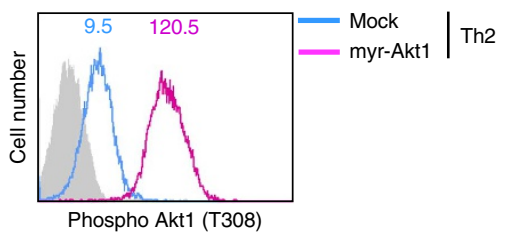

g

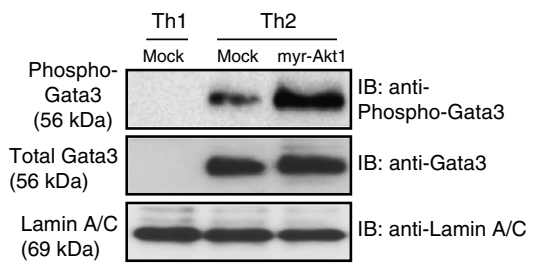

h

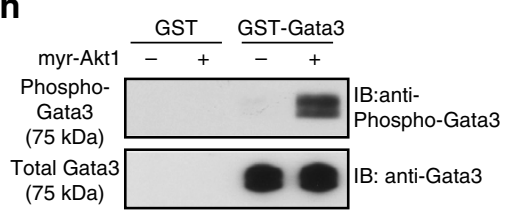

i

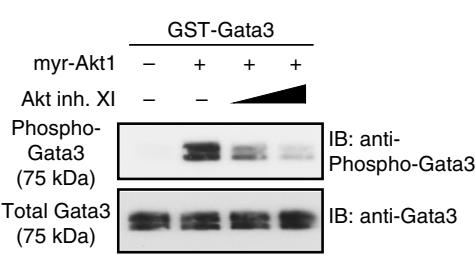

Figure 4 | Akt1 is a kinase for Gata3 phosphorylation. (a) Immunopurified Gata3 complexes from 293T cells were subjected to an in vitro kinase assay. The white arrowheads indicate the molecular size of Gata3. (b) Immunopurified Gata3 complexes from 293T cells were run on a 12\% SDS-PAGE gel containing recombinant Gata3 or myelin basic protein (MBP), followed by an in-gel kinase assay. Black arrowheads indicate the molecular size of Akt1. (c) Akt1 is detected from the band identified in Fig. 4b. Representative sequence coverage of Akt1 protein detected in a mass spectrometry analysis is shown. Red characters indicate the actual peptides detected by mass spectrometry. (d) The association of Myc-tagged myr-Akt1 with Flag-tagged Gata3 was assessed using 293T cells. (e) The amounts of phospho-Gata3 were assessed by IB with a phospho-Gata3 Ab or a Flag mAb using total lysates from Flag-tagged Gata3 and myr-Akt1 or dn Akt1-expressing 293T cells. (f,g) Naive CD4 T cells were stimulated under Th2 conditions and then infected with a retrovirus vector carrying myr-Akt1 cDNA. Four days later, intracellular staining profiles of phospho-Akt1 (Thr308) are shown. The number in the histogram represents the MFI. The grey-filled histogram shows isotype control staining (f). The amount of phospho-Gata3 was assessed by IB (g).

(h,i) Recombinant Gata3 was subjected to an in vitro phosphorylation assay using immunopurified myr-Akt1 from 293T cells with or without Akt inhibitor $\mathrm{XI}$. Five $(\mathbf{e})$, four $(\mathbf{a}, \mathbf{h})$, three $(\mathbf{d}, \mathbf{i})$ and two $(\mathbf{b}, \mathbf{f}, \mathbf{g})$ independent experiments were performed with similar results.

IFN $\gamma$ production from these memory-type Th2 cells. Antigenspecific memory Th2 cells can be efficiently generated in vivo by adoptive transfer of effector Th2 cells ${ }^{34}$. To determine the expression levels of T-bet in IFN $\gamma$-producing memory Th2 cells, the cells were divided into four distinct subpopulations according to their expression of IL-4 and IFN $\gamma$. Consistent with previous report ${ }^{35}$, we found that IFN $\gamma$-producing memory Th2 cells express higher levels of T-bet protein as compared with nonIFN $\gamma$-producing memory Th2 cells (Fig. 6a). To examine whether IFN $\gamma$ production from memory Th2 cells is T-bet-dependent, memory Th2 cells from Tbx21-deficient cells were generated. While there was no difference in effector Th2 cell differentiation between WT and Tbx21-deficient cells, IFN $\gamma$ production from Tbx21-deficient memory Th2 cells was strongly inhibited (Fig. 6b).

Gata3 is phosphorylated in IFN $\gamma$-producing memory Th2 cells. We next analysed the status of Gata3 phosphorylation in IFN $\gamma$ producing memory Th2 cells. Although the level of total Gata3 protein was slightly lower, the level of Gata3 phosphorylation, particularly the ratio of phosphorylated Gata3 to total Gata3 protein levels, was higher in IFN $\gamma$-producing cells compared with non-producing cells (Fig. 6c). The phosphorylation status of Akt1 at Thr308 in IFN $\gamma$-producing memory Th2 cells was higher than in non-producing cells, whereas there was only a marginal increase in the levels of total Akt1 and phosphorylated Akt1 at S473 (Fig. 6c). We also found that the phosphorylation levels of Gata3 were higher in IFN $\gamma$-producing memory Th2 cells according to the mean fluorescent intensity (MFI) value (53.0 versus 94.6) (Fig. 6d). Moreover, memory Th2 cells with higher Gata3 phosphorylation showed higher levels of T-bet expression. A similar positive correlation was detected in IFN $\gamma$-production and T-bet expression, in addition to Akt1 phosphorylation (pT308) (Fig. 6d). A summary of the MFI values with statistics was also evaluated (Fig. 6d, lower). Next, to address the role of Akt1 activation in IFN $\gamma$ production from memory Th2 cells, we examined the effect of an Akt inhibitor on IL-4 and IFN $\gamma$ production in memory Th2 cells. The production of IFN $\gamma$, but not IL-4, from memory Th2 cells was modestly but significantly decreased by Akt inhibitor treatment, suggesting that the production of IFN $\gamma$ is regulated by Akt in memory Th2 cells (Fig. 6e). Taken together, these results indicate that Akt1 is one of the responsible kinases for the regulation of IFN $\gamma$ production, potentially through Gata3 phosphorylation and subsequent derepression of the $T b \times 21$ expression in memory Th2 cells. 
a

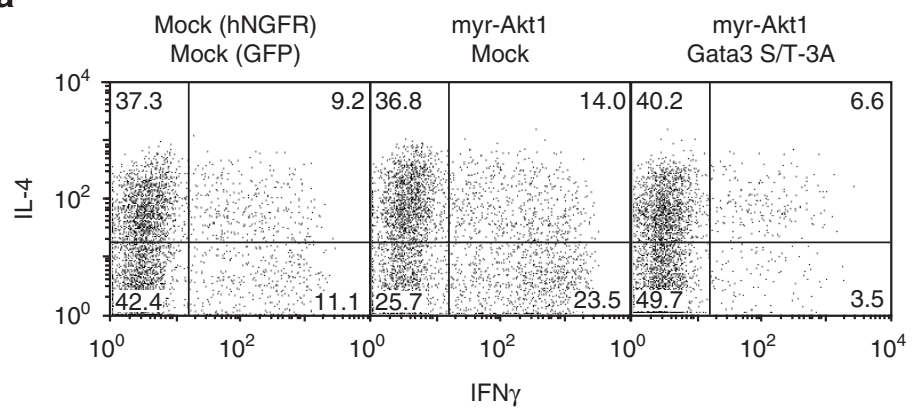

b

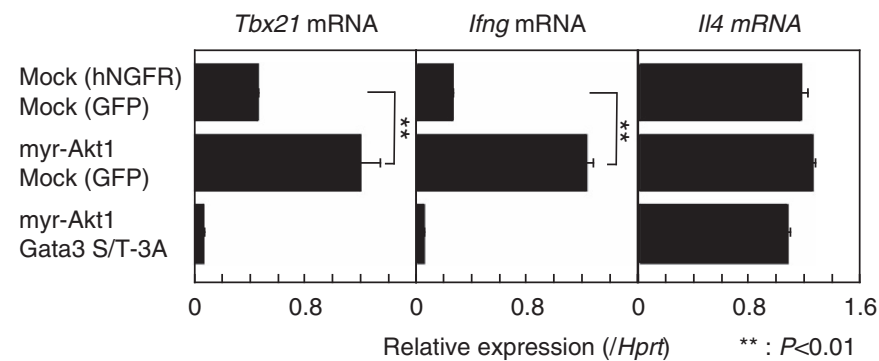

C

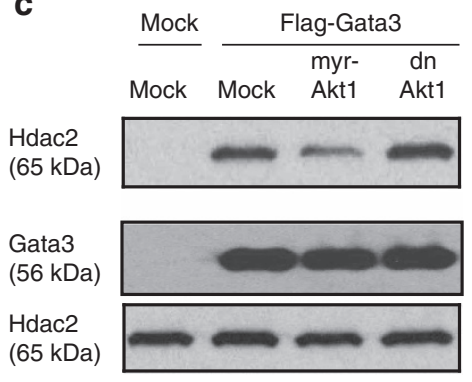

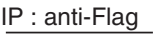

IB : anti-Myc

Total lysate

IB : anti-Flag

IB : anti-Myc

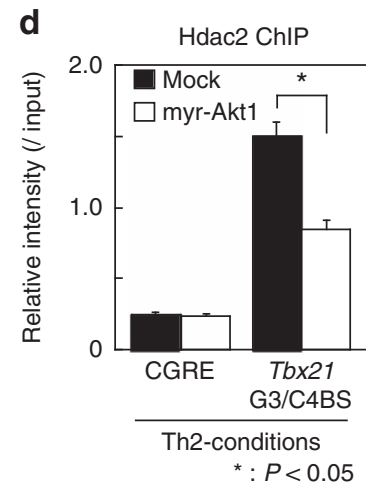

Figure $\mathbf{5}$ | Activation of Akt1 induces the derepression of the Tbx21 and lfng expression in Th2 cells. (a,b) CD4 T cells were stimulated under Th2 conditions and then infected with retrovirus vectors carrying myr-Akt1 and Gata3 S/T-3A mutant cDNAs. Four days later, the cells were subjected to IL-4 and IFN $\gamma$ staining followed by a FACS analysis. Representative IFN $\gamma /$ IL-4 profiles are shown with the percentages of cells in each quadrant (a). The levels of mRNA of Tbx21, Ifng and II4 were measured by RT-qPCR (b). (c) Total lysates from Flag-tagged Gata3 and myr-Akt1 or dn Akt1-expressing 293T cells were mixed with Myc-tagged Hdac2-expressing 293T cell lysates. Then, the amounts of Myc-tagged Hdac2 associated with Flag-tagged Gata3 were assessed. (d) Binding of Hdac2 to the CGRE and the Tbx21 G3/C4BS regions was determined by ChIP assays followed by qPCR analyses in myr-Akt1 introduced Th2 cells as in $\mathbf{a} .{ }^{\star \star} P<0.01,{ }^{\star} P<0.05$ by Student's $t$-test. Three $(\mathbf{a}, \mathbf{b})$ and two $(\mathbf{c}, \mathbf{d})$ independent experiments were performed with similar results.

GATA3 phosphorylation in human memory Th2 cells. Finally, we analysed memory-type Th2 cells from human peripheral blood. $\mathrm{CD} 4{ }^{+} \mathrm{CD} 45 \mathrm{RO}^{+}$memory $\mathrm{CD} 4 \mathrm{~T}$ cells from healthy volunteers were isolated and stimulated in vitro with phorbol 12 myristate 13-acetate (PMA) and ionomycin for $4 \mathrm{~h}$. In the human memory-type CD4 T cells, IL-4 single producers and IL-4/IFN $\gamma$ double-producers were detected (Fig. 7a, left). Similar to murine memory Th2 cells (Fig. 6), the expression levels of total GATA3 protein were lower and IL-4/IFN $\gamma$ double-producers showed higher phospho-GATA3 and T-BET protein expression as compared with IL-4 single producers (Fig. 7a). Moreover, human IL4-producing memory-type CD4 T cells with higher levels of IFN $\gamma$ expression showed higher levels of GATA3 phosphorylation and T-BET expression (Fig. 7b, left). The ratio of the MFI of phosphorylated GATA3 to the total GATA3 level was significantly higher in IFN $\gamma$-producing human memory Th2 cells as compared with IFN $\gamma$-non-producing cells (Fig. 7b, right). These results are consistent with the notion that GATA3 phosphorylation-induced derepression of T-BET expression may occur in human memorytype CD4 T cells and control the production of IFN $\gamma$.

\section{Discussion}

Gata3 organizes functionally distinct complexes with defined functions in differentiating Th2 cells and regulates the expression of a various genes in a positive and negative fashion to establish Th2 cell identity ${ }^{4,11,21,22}$. In the current study, we wished to identify the mechanisms by which the molecular switch for organizing activating and repressive Gata3 complexes occurs in Th2 cells and found that a posttranslational modification of Gata3, phosphorylation of Gata3 mediated by Akt1, plays an important role in the organization of repressive Gata3 complexes and IFN $\gamma$ expression in memory Th2 cells. Some Gata 3 molecules are phosphorylated in Th2 cells and phosphorylation mimic Gata3 has a selective defect in the inhibition of IFN $\gamma$ production. Phosphorylation of Gata3 at Ser308, Thr315 and Ser316 resulted in the dissociation of Hdac2 from the Gata3 complex, followed by derepression of Tbx21 and Ifng expression (Figs 1-3). Akt1 was identified as a Gata3 kinase (Figs 4 and 5), and the levels of Akt1 phosphorylation and subsequent Gata3 phosphorylation were significantly upregulated in IFN $\gamma$-producing memory Th2 cells (Figs 6 and 7). This study highlights a functional link between the 
a

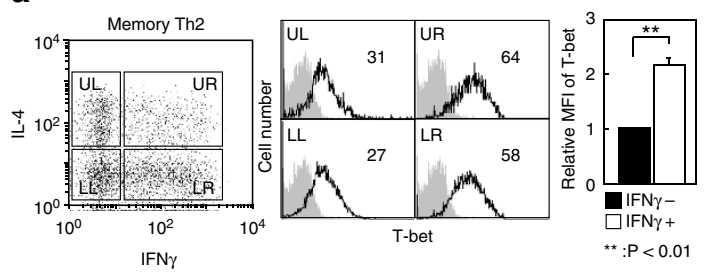

b

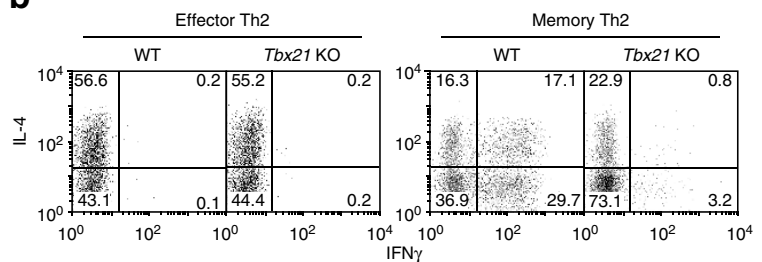

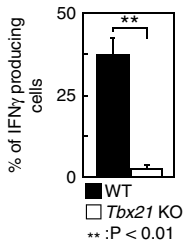

C
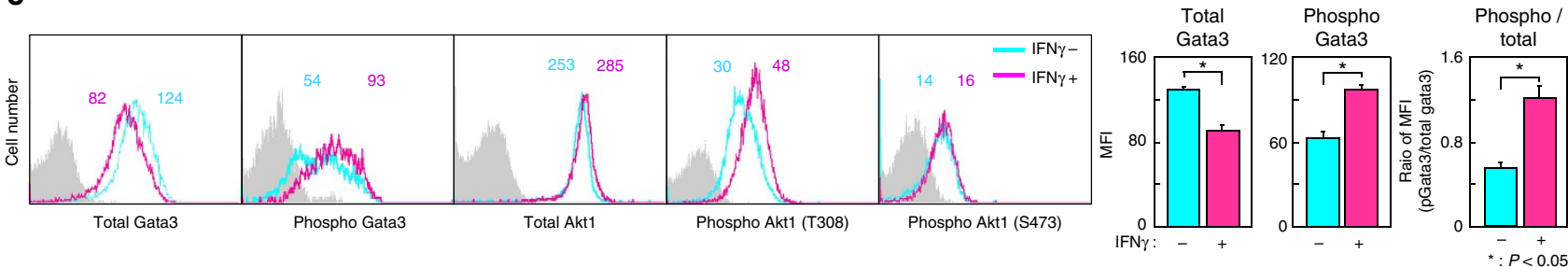

d
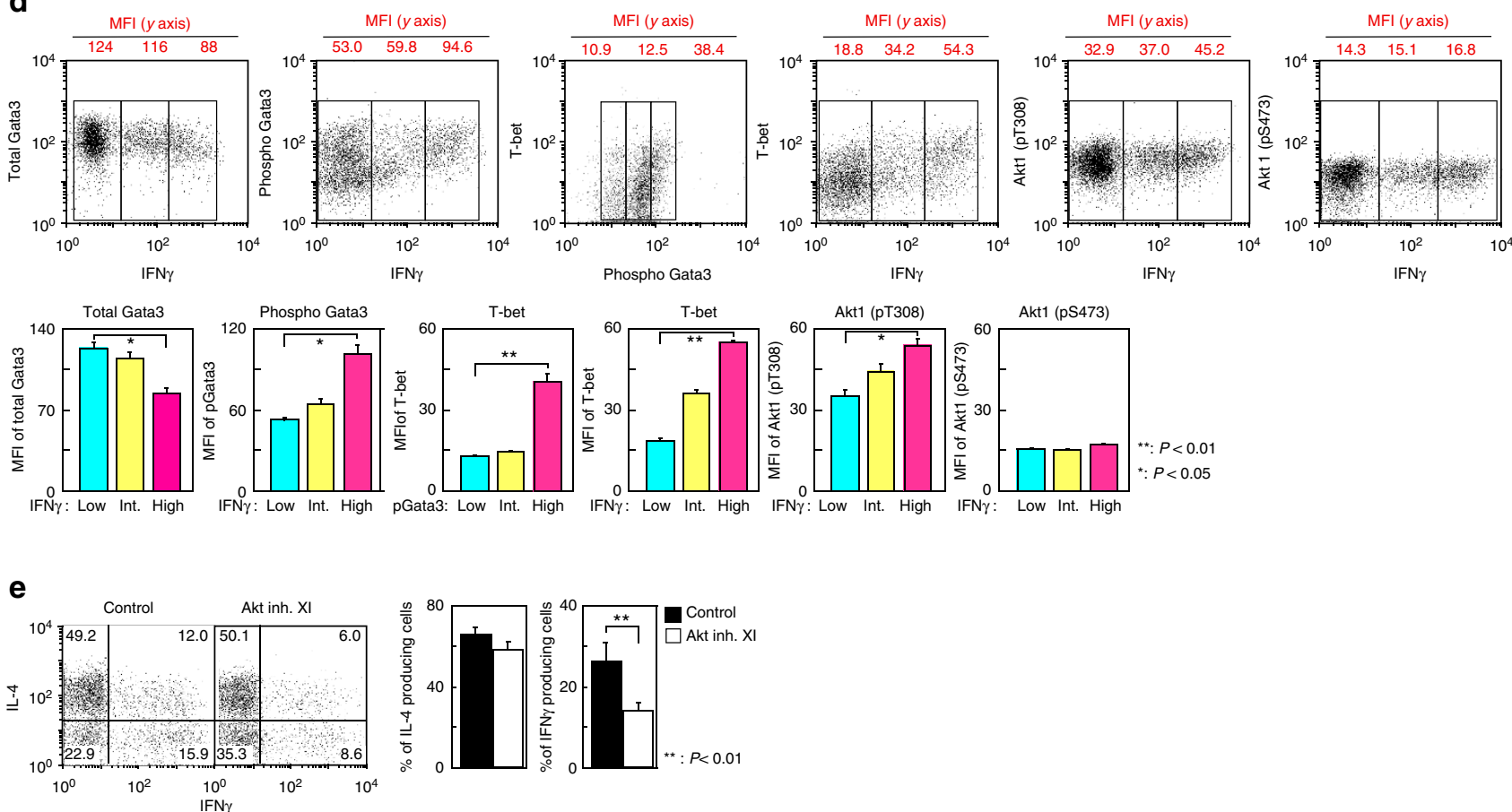

Figure 6 | Increased phosphorylation status of Gata3 and Akt1 in IFN $\gamma$-producing memory Th2 cells. (a) Memory Th2 cells were stimulated with PMA plus ionomycin for $6 \mathrm{~h}$. The cells were divided into four distinct subpopulations according to their expression of IL-4 and IFN $\gamma$ (left). Intracellular staining profiles of T-bet in these four subpopulations are shown (middle). The number in the histogram represents the MFI. The grey-filled histogram shows isotype control staining. A summary of the MFI of T-bet in IFN $\gamma$-producing and -nonproducing cells is presented (right) $(n=5)$. (b) Intracellular staining profiles of IFN $\gamma$ and IL-4 in effector and memory Th2 cells from WT or Tbx21-deficient mice are shown with the percentages of cells in each area (left). A summary of the percentage of IFN $\gamma$-producing memory Th2 cells is presented (right) $(n=3)$. (c) Intracellular staining profiles of Gata3, phospho-Gata3, Akt1 and phospho-Akt1 in IFN $\gamma$-producing and -nonproducing memory Th2 cells are shown (left). A summary of the MFI value of Gata3 and phosphoGata3 and the ratio of the MFI (phospho-Gata3/total Gata3) in IFN $\gamma$-producing and IFN $\gamma$-nonproducing memory Th2 cells is presented (right) ( $n=5$ ). (d) Intracellular staining profiles of IFN $\gamma$, Gata3, phospho-Gata3, T-bet and phospo-Akt1 are shown. The number represents the MFI of the $y$ axis in each area (top). A summary of the MFI in each area (IFN $\gamma$ : Low, Int, High) is presented (bottom) $(n=5)$. (e) Memory Th2 cells were cultured in IL-7-containing medium with or without Akt inhibitor XI $(10 \mu \mathrm{M})$ for 2 days. Intracellular staining profiles of IFN $\gamma$ and IL-4 are shown (left). A summary of the percentage of IL-4- and IFN $\gamma$-producing memory Th2 cells is presented (right) $(n=4) .{ }^{\star \star} P<0.01,{ }^{\star} P<0.05$ by Student's $t$-test. Five (a), four (e) and three (b,c, d) independent experiments were performed with similar results.

posttranslational modification of Gata3 and its strong feedforward function as a master regulator of Th2 cell differentiation and function.

An array of posttranslational modifications may orchestrate the activity of a transcription factor, including subcellular localization, protein stability, sequence-specific DNA binding, transcriptional activity and protein-protein interactions ${ }^{23}$. Regarding the master transcription factors for Th cell subset differentiation, some pioneer studies have reported several interesting examples; Itk-mediated tyrosine phosphorylation of T-bet controls its interaction with Gata3 (ref. 32), ubiquitination of Foxp3 induced by Stub1 regulates the stability of Foxp3 protein ${ }^{36}$, cyclin-dependent kinase 2 (CDK2)-mediated phosphorylation of Gata3 at Thr156 regulates Fbw7-dependent Gata3 ubiquitylation and degradation in the thymus ${ }^{27}$, and methylation of Gata3 at Arg261 regulates the transcriptional 
a

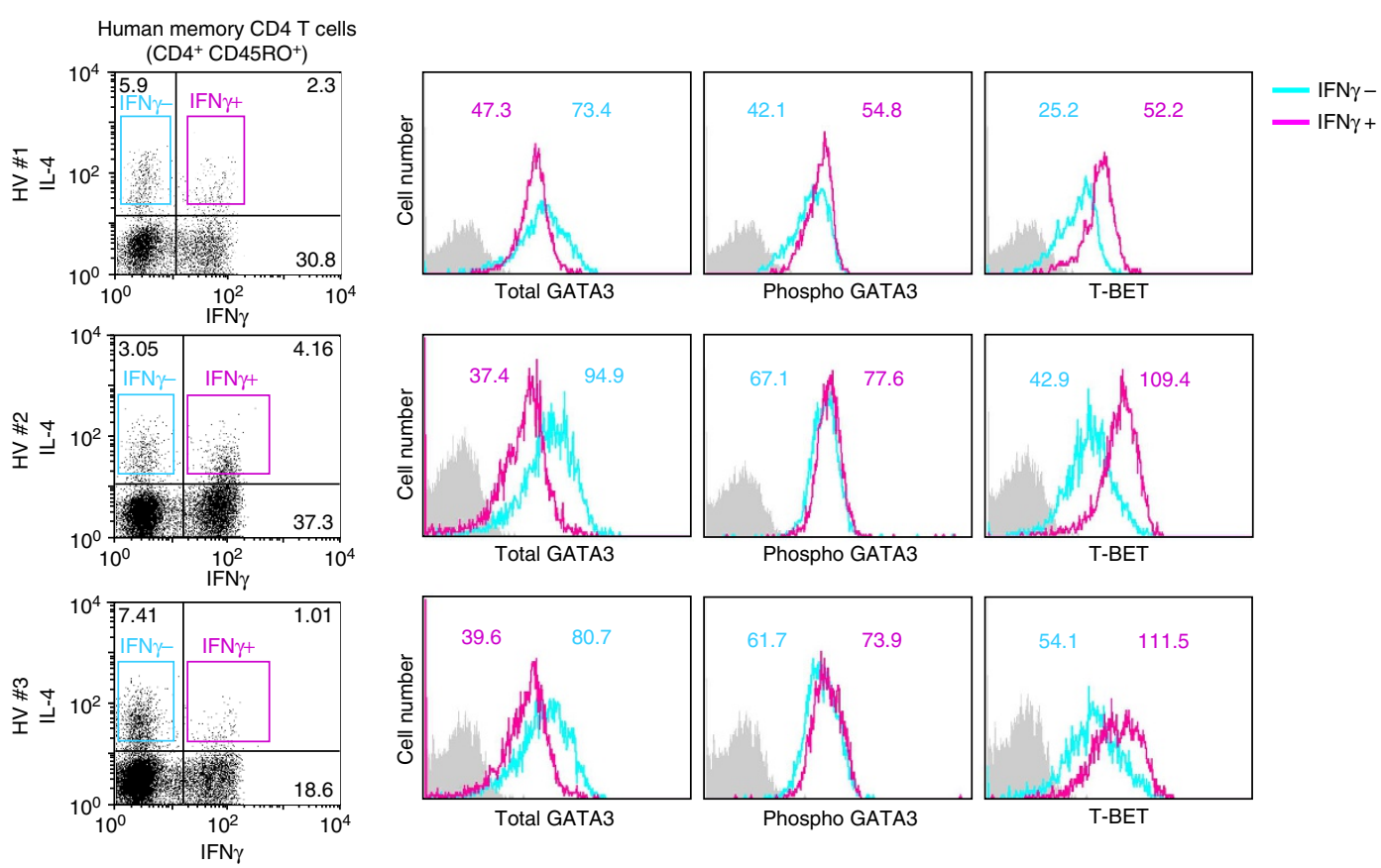

b

IL-4-producing human memory CD4 T cells $\left(\mathrm{CD} 4^{+} \mathrm{CD} 45 \mathrm{RO}^{+} \mathrm{IL}-4^{+}\right)$
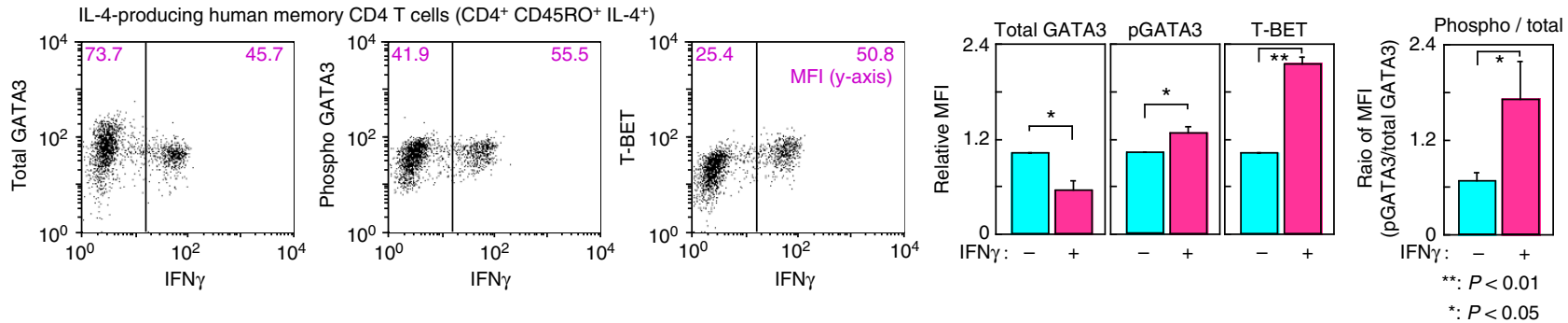

Figure 7 | GATA3 phosphorylation in human IL-4 and IFN $\gamma$-double-producing memory-type CD4 T cells. (a) Human CD45RO ${ }^{+}$memory CD4 T cells from peripheral blood were purified and stimulated in vitro for $4 \mathrm{~h}$. Intracellular staining profiles of GATA3, phosopho-GATA3 and T-BET in IL-4 ${ }^{+} / \mathrm{IFN}^{-}{ }^{-}$ $\left(\mathrm{IFN} \gamma^{-}\right)$or IL-4 ${ }^{+} / \mathrm{IFN} \gamma^{+}\left(\mathrm{IFN} \gamma^{+}\right)$memory CD4 T cells are shown. Representative IFN $\gamma / \mathrm{IL}-4$ profiles are shown with percentages of cells in each quadrant (left). The number in the histogram represents the MFI. The grey-filled histogram shows isotype control staining. Experiments using three healthy donor volunteers (HV\#1-3) are shown. (b) Human CD45RO ${ }^{+}$memory CD4 T cells were stimulated and the intracellular staining profiles of IFN $\gamma$, GATA3, phospho-GATA3 and T-BET are shown with the MFI of the $y$ axis in each area (left). A summary of the MFI of GATA3, phospho-GATA3 and T-BET and the ratio of the MFI (phospho-GATA3/total GATA3) in IFN $\gamma$-producing and IFN $\gamma$-nonproducing memory Th2 cells is presented (right) ( $n=3$ ). ${ }^{* \star} P<0.01$, ${ }^{\star} P<0.05$ by Student's $t$-test. Experiments using three healthy donor volunteers were performed with similar results.

activation of the $\mathrm{Il} 5$ gene in Th2 cells ${ }^{22}$. We herein demonstrate that phosphorylation of Gata3 at Ser308, Thr315 and Ser316 controls the repressive function of Gata3 on IFN $\gamma$ expression via the dissociation of Hdac2 from the Gata3/Chd4 repressive complex. Similar examples have been reported in p53-MDM2 systems $^{37,38}$. Phosphorylation of p53 at Ser15 and Ser37 induces a significant change in $\mathrm{p} 53$ conformation and resulted in the impaired ability of MDM2 to inhibit p53-dependent transactivation $^{38}$.

Akt1 phosphorylates several transcription factors, including Foxo1, CREB, Gata1 and Gata2, and regulates their functions by various distinct mechanisms ${ }^{26,39-41}$. Akt1-mediated phosphorylation of Foxo1 at Thr24 and Ser253 induces nuclear export and transcriptional inactivation of Foxo1 (ref. 39). CREB is phosphorylated by Akt1 at Ser133, and the phosphorylation of CREB induced targeted gene expression by prompting the recruitment of co-activator $\mathrm{CBP}^{41}$. Phosphorylation of Gatal at Ser310 is induced by Akt1 and is required for the transcriptional activity of Gatal in erythroid cells ${ }^{40}$. Akt1-dependent phosphorylation at Ser401 of Gata2 controls its subcellular localization in adipocytes $^{26}$. Thus, Aktl phosphorylates several transcription factors and positively and negatively regulates their functions. We herein demonstrate another example of negative regulation by Akt1mediated phosphorylation: Akt1 phosphorylates Gata3 and induces the dissociation of Hdac2 from the Gata3 complex, resulting in a failure in the repression of IFN $\gamma$ expression in Th2 cells.

Th2 cells are thought to be an intrinsically stable lineage that possesses a programme to produce IL-4, IL- 5 and IL-13, and the machinery to inhibit the expression of IFN $\gamma$ (ref. 42). However, after viral infection, previously committed Th2 cells stably co-expressing Gata3 and T-bet show the features of both Th1 and Th2 cells ${ }^{6}$. In addition, several investigators have reported IFN $\gamma$-producing Th2 cells under various in vivo and in vitro conditions ${ }^{43,44}$. As shown in Figs 6 and 7, memory-type Th2 cells that express IFN $\gamma$ can be easily detected in both murine and human systems. Thus, the current findings of Akt1-mediated phosphorylation of Gata3, the organization of repressive Gata3 complexes and the repression of IFN $\gamma$ expression may operate under physiological conditions. Memory-type Th2 cells that express IFN $\gamma$ may play an important role in the pathogenesis of a mixed-type inflammation with infiltration of eosinophils and neutrophils ${ }^{45,46}$. 
We found that the levels of Aktl phosphorylation at Thr308 were substantially higher in IFN $\gamma$-producing memory Th2 cells, while there was only a marginal increase in the total Akt1 levels in IFN $\gamma$-producing cells as compared with non-producing cells (Fig. 6c). These results may indicate that the activation of Akt1 is more important than the expression of Akt1 itself in the regulation of IFN $\gamma$ production in memory Th2 cells. The upstream signals that control Akt1 activity appear to be important in the selective activation of Akt1 in IFN $\gamma$-producing memory Th2 cells. We also found that the IFN $\gamma$ production from memory Th2 cells was significantly inhibited by Akt inhibitor treatment (Fig. 6e). While we have not determined whether Akt1 is necessary for the generation of IFN $\gamma$-producing Th2 cells, this result may indicate that the Akt activity plays a pivotal role in the maintenance of IFN $\gamma$-producing ability in memory Th2 cells. Thus, further study is required to clarify which signals (via TCR, co-receptors or cytokine receptors) confer the selective activation of Akt1 in IFN $\gamma$-producing Th2 cells and how IFN $\gamma$-producing Th2 cells are generated in vivo. Further detailed analyses of the posttranslational modifications of Gata3 and identification of responsible enzymes may lead to the discovery of novel therapeutic targets for Th2-mediated, IFN $\gamma$-involved chronic inflammatory disorders, including atopic dermatitis or chronic airway inflammatory disorders.

HDR syndrome (hypoparathyroidism, deafness, renal disease) is an autosomal dominant disease characterized by the triad hypoparathyroidism, hearing loss and renal dysplasia ${ }^{24}$. In addition to T lymphocytes, Gata3 expression is observed in the developing parathyroid glands, inner ear and kidneys in humans and mice ${ }^{47}$. Loss-of-function mutations of GATA3 have been reported to be associated with HDR syndrome ${ }^{24}$. Interestingly, an in-frame deletion of amino acids 315-318 in GATA3 was found in patients with familial HDR syndrome. This deletion involves Cys317, which binds to zinc ions to stabilize the zinc finger structure. Since phosphorylation of GATA3 at Thr315 and Ser316 modulates the function of GATA3, it is of particular interest to study the pathophysiological roles of GATA3 phosphorylation in HDR syndrome.

In summary, Akt1-mediated phosphorylation of Gata3 plays an important role in the organization of repressive Gata3 complexes and IFN $\gamma$ repression in Th2 cells. The findings presented herein highlight a pivotal role of posttranslational modification of Gata3 in the organization of Gata3 complexes and its strong feed-forward function as a master regulator of Th2 cell differentiation and function.

\section{Methods}

Mice. All of experiments were performed using 6-8-week-old female mice. $\mathrm{C} 57 \mathrm{BL} / 6, \mathrm{BALB} / \mathrm{c}$ and BALB/c $n u / n u$ mice were purchased from CLEA Co. (Tokyo, Japan). OVA-specific TCR- $\alpha \beta$ (DO11.10) transgenic (Tg) mice (BALB/c background) were provided by Dr D. Loh (Washington University School of Medicine, St Louis). Tbx21-deficient mice (DO11.10 Tg, BALB/c background) were kindly provided by Dr Laurie Glimcher (Cornell University). All mice were maintained under specific pathogen-free conditions. Animal care was conducted in accordance with the guidelines of Chiba University.

Generation of Th1 and Th2 cells. CD4 T cells with a naive phenotype (CD44 ${ }^{\text {low }}$ ) were purified using a FACSAria machine (Becton Dickinson, San Jose, CA) yielding a purity of $>98 \%$ and stimulated with $3 \mu \mathrm{g} \mathrm{ml}^{-1}$ of immobilized anti-TCR $\beta \mathrm{mAb}$ plus $1 \mu \mathrm{g} \mathrm{ml}{ }^{-1}$ anti-CD28 $\mathrm{mAb}$ under Th1 or Th2 conditions in vitro. The cells were then transferred to new dishes and cultured for another $3-4$ days in the presence of only the cytokines present in the initial culture. Th1 conditions were as follows: $25 \mathrm{U} \mathrm{ml}^{-1}$ of IL-2, $10 \mathrm{U} \mathrm{ml}^{-1}$ of IL- 12 and an anti-IL-4 mAb. Th2 conditions were as follows: $25 \mathrm{U} \mathrm{ml}^{-1} \mathrm{IL}-2,10 \mathrm{U} \mathrm{ml}^{-1} \mathrm{IL}-4$, and anti-IL12 and anti-IFN $\gamma$ mAbs.

Generation of memory Th2 cells. Naive CD4 T cells from DO11.10 Tg mice were cultured with $300 \mathrm{nM}$ OVA peptide (Loh15, OVA 323-339) and Thy1.2-depleted $\mathrm{BALB} / \mathrm{c}$ irradiated spleen cells for 6 days under Th2 conditions. Effector Th2 cells $\left(3 \times 10^{7}\right)$ were then transferred intravenously to syngeneic $\mathrm{BALB} / \mathrm{c} \mathrm{nu} / \mathrm{nu}$ mice. Five weeks after cell transfer, $\mathrm{CD} 4{ }^{+}$and $\mathrm{KJ}^{+}$cells in the spleen were purified by auto-MACS (Miltenyi Biotec, Bergisch Gladbach, Germany) and used as memory Th2 cells. For the Akt inhibitor treatment, memory Th2 cells were cultured with IL-7 $\left(10 \mathrm{U} \mathrm{ml}^{-1}\right)$ in the presence or absence of Akt inhibitor XI $(10 \mu \mathrm{M})$ for 2 days

Identification of Gata3 phosphorylation sites. Flag-tagged cDNA for Gata3 was inserted into a multi-cloning site of the CS-CDF-EG-internal ribosome entry site (IRES)-green fluorescent protein (GFP)-PRE vector. The lentivirus vector-containing culture supernatant was prepared as described previously ${ }^{48}$. D10G4.1 cells were infected with either mock control (CS-CDF-E $\alpha$-IRES-GFPPRE) or Flag-Gata3 (CS-CDF-E $\alpha$-Flag-Gata3-IRES-GFP-PRE)-containing lentiviruses. Three days after infection, GFP-positive lentivirus-infected cells were sorted with a FACSAria machine (Becton Dickinson). Flag-tagged-Gata3 or mock-infected D10G4.1 cells were solubilized with the following protease inhibitor-containing IP buffer: $50 \mathrm{mM}$ Tris- $\mathrm{HCl}$ (pH 7.5), $150 \mathrm{mM} \mathrm{NaCl}, 10 \%$ glycerol, $0.1 \%$ Tween, $1 \mathrm{mM}$ EDTA, $10 \mathrm{mM} \mathrm{NaF}, 1 \mathrm{mM}$ DTT and a protease inhibitor cocktail (Roche Applied Science, Indianapolis, IN), and lysed on ice for 30 min with gentle shaking and sonication with a Misonix sonicator (Misonix, Farmingdale, NY). The insoluble materials were removed by centrifugation and immunoprecipitation with anti-Flag M2 agarose (Sigma-Aldrich, St Louis, MO) was performed overnight at $4{ }^{\circ} \mathrm{C}$. Immune complexes were eluted from the agarose by $3 x$ Flag peptide, and the eluted Gata3 complexes were immunoprecipitated with an anti-Gata3 mAb (HG3-31, Santa Cruz Biotechnology, Inc. Santa Cruz, CA) or control IgG coupled to protein A/G beads. Immune complexes were eluted from the beads with elution buffer ( $50 \mathrm{mM}$ Tris- $\mathrm{HCl} \mathrm{pH} \mathrm{8.0,1 \%} \mathrm{SDS,} 10 \mathrm{mM}$ EDTA) and separated by SDS-PAGE. The bands were excised from the gel and subjected to a mass spectrometric analysis to identify corresponding proteins. The gel pieces were washed twice with $100 \mathrm{mM}$ bicarbonate in acetonitrile and the proteins were digested with trypsin. After adding $0.1 \%$ formic acid to the supernatant, the peptides were analysed by LC-MS/MS with a LTQ Mass Spectrometer (Thermo Scientific, Waltham, MA). The resulting MS/MS data set was analysed using the Mascot software programme (Matrix Science, Boston, MA).

Immunoprecipitation and immunoblotting. Anti-Flag mAb (M2, Sigma-Aldrich) anti-Myc mAb (PL14) and anti-phospho Gata3 Ab (ab61052, Abcam, Cambridge, MA) were used for immunoprecipitation. Protein extracts from the transfected cells were prepared using RIPA buffer (1\% NP-40, 0.25\% Na-deoxycholate, $150 \mathrm{mM}$ $\mathrm{NaCl}, 1 \mathrm{mM}$ EDTA, $1 \mathrm{mM}$ PMSF, $1 \mu \mathrm{g} \mathrm{ml}^{-1}$ of aprotinin, leupeptin and pepstain, $1 \mathrm{mM} \mathrm{Na}_{3} \mathrm{VO}_{4}, 1 \mathrm{mM} \mathrm{NaF}$ and Tris- $\mathrm{HCl}, 50 \mathrm{mM}, \mathrm{pH}$ 7.4). For immunoprecipitation analyses, the cell lysates were subjected to a pre-clear process with protein G-sepharose at $4^{\circ} \mathrm{C}$ for $1 \mathrm{~h}$ with rotation. The pre-cleared extracts were then subjected to immunoprecipitation with an anti-Flag mAb or an anti-phospho Gata3 $\mathrm{Ab}$ at $4{ }^{\circ} \mathrm{C}$ for $2 \mathrm{~h}$, and then the immunocomplexes were precipitated with protein G-sepharose beads at $4^{\circ} \mathrm{C}$ for $1 \mathrm{~h}$. For immunoblot analyses, immunoprecipitates were eluted from beads in SDS-gel-loading buffer and run on $10 \%$ or $8-16 \%$ gradient polyacrylamide gels. After electrophoresis, the proteins were subjected to immunoblotting. The antibodies used for the Immunoblot analyses were anti-Gata3 (1 $\left.\mu \mathrm{g} \mathrm{ml}^{-1}, \mathrm{HG} 3-31\right)$, anti-phospho Gata3 Ab $\left(1 \mu \mathrm{g} \mathrm{ml}{ }^{-1}\right.$, ab61052, Abcam), antiFlag $\left(1 \mu \mathrm{g} \mathrm{ml}^{-1}, \mathrm{M} 2\right)$, anti-Myc $\left(1 \mu \mathrm{g} \mathrm{ml}^{-1}\right.$, PL14), anti-Lamin A/C $\left(1 \mu \mathrm{g} \mathrm{ml}^{-1}\right.$, $\mathrm{H}-110$, Santa Cruz Biotechnology, Inc.) and anti-HA $\left(1 \mu \mathrm{g} \mathrm{ml}^{-1}, 3 \mathrm{~F} 10\right.$, Roche, Basel, Switzerland). Images have been cropped for presentation. Full-size images are presented in Supplementary Fig. 1.

Retroviral vectors and infection. The retrovirus vector, pMXs-IRES-GFP, was provided by Dr T. Kitamura (The University of Tokyo, Tokyo, Japan). The methods used to generate the virus-supernatant and for infection were described previously ${ }^{49}$. Infected cells were collected 5 days after stimulation and subjected to a quantitative reverse transcription-PCR (RT-qPCR) analysis and intracellular staining with anti-IL-4, anti-IFN $\gamma$ and anti-Akt1.

Quantitative RT-PCR. Total RNA was isolated using TRIzol reagent (Invitrogen, Waltham, MA). Reverse transcription was performed using the Superscript II kit (Invitrogen). For quantitative real-time PCR, a TaqMan universal PCR master mix was used for all reactions (Applied Biosystems, Waltham, MA) with an ABI Prism 7500 Sequence Detection System. Primers and probes used for the detection of Tbx21, Il4, Ifng and Hprt were described previously ${ }^{5}$. The data are shown as the relative expression normalized to Hprt signal.

Chromatin immunoprecipitation assay. ChIP assays were performed using anti-Gata3 (D-16, Santa Cruz Biotechnology, Inc.), anti-p300 (N-15, Santa Cruz Biotechnology, Inc.) and Hdac2 (ab12169, Abcam) antibodies as described previously ${ }^{33}$. Quantitative-PCR analyses were performed on an ABI prism 7500 real-time PCR machine with probes from the Roche Universal Probe Library System. The specific primers and TaqMan probes used in this report were described previously ${ }^{4}$. 
Expression plasmids. Flag-tagged Gata3 (pFlag-CMV2-Gata3) mutants were generated by a PCR-based method. Myc-tagged $\mathrm{N}$-terminal myristoylation and dn Akt1 were purchased from Millipore (Temecula, CA). Expression plasmids were transfected into 293T cells using FuGENE reagent (Roche) according to the manufacturer's protocol.

In vitro kinase assay. Flag-tagged Gata3 complexes were immunopurified from $293 \mathrm{~T}$ cells. Immunoprecipitates were incubated at $30^{\circ} \mathrm{C}$ for $30 \mathrm{~min}$ in $40 \mathrm{mM}$ HEPES (pH 7.5), $15 \mathrm{mM} \mathrm{MgCl} 2,0.1 \mathrm{mM}$ EDTA, $5 \mathrm{mM}$ 2-mercaptoethanol (2-ME), $25 \mu \mathrm{M}$ cold ATP and $5 \mu \mathrm{Ci}$ of $\left[\gamma_{-}{ }^{32} \mathrm{P}\right] \mathrm{ATP}$. Phosphorylated Gata3 was analysed by SDS-PAGE and autoradiography.

In-gel kinase assay. Flag-tagged Gata3 complexes from 293T cells were run on a $12 \%$ SDS-PAGE gel with the resolving gel containing $0.02 \%$ recombinant GST-Gata3 or myelin basic protein as a negative control. After the electrophoretic run, the gel was washed with $50 \mathrm{mM}$ Tris- $\mathrm{HCl}(\mathrm{pH} 8.0), 20 \%$ 2-propanol and $50 \mathrm{mM}$ Tris- $\mathrm{HCl}(\mathrm{pH} 8.0)$ and $5 \mathrm{mM} \mathrm{2-ME}$. The proteins were subsequently denatured in $50 \mathrm{mM}$ Tris- $\mathrm{HCl}$ ( $\mathrm{pH} 8.0), 5 \mathrm{mM} 2-\mathrm{ME}$, and $8 \mathrm{M}$ guanidinium hydrochloride for $2 \mathrm{~h}$. Proteins were then slowly renatured over a period of $16 \mathrm{~h}$ with six changes in a buffer containing $50 \mathrm{mM}$ Tris- $\mathrm{HCl}(\mathrm{pH} 8.0), 5 \mathrm{mM} 2-\mathrm{ME}$ and $0.04 \%$ Tween 20 . The gel was equilibrated in a buffer containing $40 \mathrm{mM}$ HEPES (pH 7.5), $15 \mathrm{mM} \mathrm{MgCl}_{2}, 0.1 \mathrm{mM}$ EDTA, $5 \mathrm{mM}$ 2-ME for $90 \mathrm{~min}$ and then incubated in the same buffer containing $10 \mu \mathrm{Ci}$ of $\left[\gamma^{32} \mathrm{P}\right] \mathrm{ATP}$. After washing, the gel was dried and subjected to autoradiography.

Preparation of human memory CD4 T cells. Whole blood was obtained from four healthy donor volunteers. The protocol was approved by the Institutional Ethics Committee (no. 1016). peripheral blood mononuclear cells were isolated by Ficoll-Paque (Pharmacia-Upjohn, Uppsala, Sweden) gradient centrifugation. $\mathrm{CD}_{5} \mathrm{RO}^{+}$memory CD4 T cells were purified using the memory CD4 ${ }^{+} \mathrm{T}$-cell isolation kit (Miltenyi Biotec) and auto-MACS (Miltenyi Biotec). Then, cells were stimulated with PMA $\left(10 \mathrm{ng} \mathrm{ml}^{-1}\right)$ and ionomycin $(500 \mathrm{nM})$ for $4 \mathrm{~h}$ and subjected to intracellular staining with anti-IL-4, anti-GATA3, anti-phospho GATA3, anti-T-BET and anti-IFN $\gamma$.

\section{References}

1. Reiner, S. L. Development in motion: helper T cells at work. Cell 129, 33-36 (2007).

2. Zhu, J., Yamane, H. \& Paul, W. E. Differentiation of effector CD4 T cell populations. Annu. Rev. Immunol. 28, 445-489 (2010).

3. Yamashita, M. et al. Essential role of GATA3 for the maintenance of type 2 helper $\mathrm{T}$ (Th2) cytokine production and chromatin remodeling at the Th2 cytokine gene loci. J. Biol. Chem. 279, 26983-26990 (2004).

4. Hosokawa, H. et al. Functionally distinct Gata3/Chd4 complexes coordinately establish T helper 2 (Th2) cell identity. Proc. Natl Acad. Sci. USA 110, 4691-4696 (2013).

5. Yamashita, M. et al. Crucial role of MLL for the maintenance of memory T helper type 2 cell responses. Immunity 24, 611-622 (2006).

6. Hegazy, A. N. et al. Interferons direct Th2 cell reprogramming to generate a stable GATA- $3(+)$ T-bet $(+)$ cell subset with combined Th2 and Th1 cell functions. Immunity 32, 116-128 (2010).

7. Endo, Y., Hirahara, K., Yagi, R., Tumes, D. J. \& Nakayama, T. Pathogenic memory type Th2 cells in allergic inflammation. Trends Immunol. 35, 69-78 (2014).

8. Soudja, S. M. et al. Memory-T-cell-derived interferon-gamma instructs potent innate cell activation for protective immunity. Immunity 40, 974-988 (2014).

9. Rothenberg, E. V. \& Scripture-Adams, D. D. Competition and collaboration: GATA-3, PU.1, and Notch signaling in early T-cell fate determination. Semin. Immunol. 20, 236-246 (2008).

10. Hosoya, T., Maillard, I. \& Engel, J. D. From the cradle to the grave: activities of GATA-3 throughout T-cell development and differentiation. Immunol. Rev. 238, 110-125 (2010).

11. Ho, I. C., Tai, T. S. \& Pai, S. Y. GATA3 and the T-cell lineage: essential functions before and after T-helper-2-cell differentiation. Nat. Rev. Immunol. 9, 125-135 (2009)

12. Tindemans, I., Serafini, N., Di Santo, J. P. \& Hendriks, R. W. GATA-3 function in innate and adaptive immunity. Immunity 41, 191-206 (2014).

13. Onodera, A. et al. STAT6-mediated displacement of polycomb by trithorax complex establishes long-term maintenance of GATA3 expression in T helper type 2 cells. J. Exp. Med. 207, 2493-2506 (2010).

14. Nakayama, T. \& Yamashita, M. Initiation and maintenance of Th2 cell identity. Curr. Opin. Immunol. 20, 265-271 (2008).

15. Kurata, H., Lee, H. J., O'Garra, A. \& Arai, N. Ectopic expression of activated Stat6 induces the expression of Th2-specific cytokines and transcription factors in developing Th1 cells. Immunity 11, 677-688 (1999).
16. Yamashita, M. et al. Ras-ERK MAPK cascade regulates GATA3 stability and Th2 differentiation through ubiquitin-proteasome pathway. J. Biol. Chem. 280, 29409-29419 (2005).

17. Shinnakasu, R. et al. Gfil-mediated stabilization of GATA3 protein is required for Th2 cell differentiation. J. Biol. Chem. 283, 28216-28225 (2008).

18. Hosokawa, H. et al. Regulation of Th2 cell development by Polycomb group gene bmi-1 through the stabilization of GATA3. J. Immunol. 177, 7656-7664 (2006).

19. Zhu, J. et al. Conditional deletion of Gata3 shows its essential function in $\mathrm{T}(\mathrm{H}) 1-\mathrm{T}(\mathrm{H}) 2$ responses. Nat. Immunol. 5, 1157-1165 (2004).

20. Zheng, W. \& Flavell, R. A. The transcription factor GATA-3 is necessary and sufficient for Th2 cytokine gene expression in CD4 T cells. Cell 89, 587-596 (1997).

21. Hosokawa, H. et al. Gata3/Ruvbl2 complex regulates T helper 2 cell proliferation via repression of Cdkn2c expression. Proc. Natl Acad. Sci. USA 110, 18626-18631 (2013).

22. Hosokawa, H. et al. Methylation of Gata3 at Arg261 regulates transactivation of the Il5 gene in T helper 2 cells. J. Biol. Chem. 290, 13095-13103 (2015).

23. Filtz, T. M., Vogel, W. K. \& Leid, M. Regulation of transcription factor activity by interconnected post-translational modifications. Trends Pharmacol. Sci. 35 , 76-85 (2014).

24. Lin, K. R., Li, C. L., Yen, J. J. \& Yang-Yen, H. F. Constitutive phosphorylation of GATA-1 at serine(2)(6) attenuates the colony-forming activity of erythrocytecommitted progenitors. PLoS ONE 8, e64269 (2013).

25. Zhao, W., Kitidis, C., Fleming, M. D., Lodish, H. F. \& Ghaffari, S. Erythropoietin stimulates phosphorylation and activation of GATA-1 via the PI3-kinase/AKT signaling pathway. Blood 107, 907-915 (2006).

26. Menghini, R. et al. Phosphorylation of GATA2 by Akt increases adipose tissue differentiation and reduces adipose tissue-related inflammation: a novel pathway linking obesity to atherosclerosis. Circulation 111, 1946-1953 (2005).

27. Kitagawa, K. et al. Fbw7 targets GATA3 through cyclin-dependent kinase 2-dependent proteolysis and contributes to regulation of T-cell development. Mol. Cell Biol. 34, 2732-2744 (2014).

28. Takemoto, N., Arai, K. \& Miyatake, S. Cutting edge: the differential involvement of the N-finger of GATA-3 in chromatin remodeling and transactivation during Th2 development. J. Immunol. 169, 4103-4107 (2002).

29. Shinnakasu, R. et al. Critical YxKxHxxxRP motif in the C-terminal region of GATA3 for its DNA binding and function. J. Immunol. 177, 5801-5810 (2006).

30. Chen, Y. et al. DNA binding by GATA transcription factor suggests mechanisms of DNA looping and long-range gene regulation. Cell Rep. 2, 1197-1206 (2012).

31. Bates, D. L., Chen, Y., Kim, G., Guo, L. \& Chen, L. Crystal structures of multiple GATA zinc fingers bound to DNA reveal new insights into DNA recognition and self-association by GATA. J. Mol. Biol. 381, 1292-1306 (2008).

32. Hwang, E. S., Szabo, S. J., Schwartzberg, P. L. \& Glimcher, L. H. T helper cell fate specified by kinase-mediated interaction of T-bet with GATA-3. Science 307, 430-433 (2005).

33. Yamashita, M. et al. Identification of a conserved GATA3 response element upstream proximal from the interleukin-13 gene locus. J. Biol. Chem. 277, 42399-42408 (2002).

34. Nakayama, T. \& Yamashita, M. Critical role of the Polycomb and Trithorax complexes in the maintenance of CD4 T cell memory. Semin. Immunol. 21, 78-83 (2009)

35. Peine, M. et al. Stable T-bet $(+)$ GATA-3(+) Th1/Th2 hybrid cells arise in vivo, can develop directly from naive precursors, and limit immunopathologic inflammation. PLoS Biol. 11, e1001633 (2013).

36. Chen, Z. et al. The ubiquitin ligase Stub1 negatively modulates regulatory $\mathrm{T}$ cell suppressive activity by promoting degradation of the transcription factor Foxp3. Immunity 39, 272-285 (2013).

37. Knights, C. D., Liu, Y., Appella, E. \& Kulesz-Martin, M. Defective p53 post-translational modification required for wild type p53 inactivation in malignant epithelial cells with $\mathrm{mdm} 2$ gene amplification. J. Biol. Chem. 278, 52890-52900 (2003).

38. Shieh, S. Y., Ikeda, M., Taya, Y. \& Prives, C. DNA damage-induced phosphorylation of p53 alleviates inhibition by MDM2. Cell 91, 325-334 (1997).

39. Biggs, 3rd W. H., Meisenhelder, J., Hunter, T., Cavenee, W. K. \& Arden, K. C. Protein kinase B/Akt-mediated phosphorylation promotes nuclear exclusion of the winged helix transcription factor FKHR1. Proc. Natl Acad. Sci. USA 96, 7421-7426 (1999).

40. Kadri, Z. et al. Phosphatidylinositol 3-kinase/Akt induced by erythropoietin renders the erythroid differentiation factor GATA-1 competent for TIMP-1 gene transactivation. Mol. Cell Biol. 25, 7412-7422 (2005).

41. $\mathrm{Du}, \mathrm{K}$. \& Montminy, M. CREB is a regulatory target for the protein kinase Akt/PKB. J. Biol. Chem. 273, 32377-32379 (1998).

42. Kanno, Y., Vahedi, G., Hirahara, K., Singleton, K. \& O’Shea, J. J. Transcriptional and epigenetic control of $\mathrm{T}$ helper cell specification: 
molecular mechanisms underlying commitment and plasticity. Annu. Rev. Immunol. 30, 707-731 (2012).

43. Motomura, Y. et al. The transcription factor E4BP4 regulates the production of IL-10 and IL-13 in CD4 + T cells. Nat. Immunol. 12, 450-459 (2011).

44. Endo, Y. et al. Eomesodermin controls interleukin-5 production in memory T helper 2 cells through inhibition of activity of the transcription factor GATA3. Immunity 35, 733-745 (2011).

45. Hansen, G., Berry, G., DeKruyff, R. H. \& Umetsu, D. T. Allergen-specific Th1 cells fail to counterbalance Th2 cell-induced airway hyperreactivity but cause severe airway inflammation. J. Clin. Invest. 103, 175-183 (1999).

46. Stein, J. et al. Non-eosinophilic airway hyper-reactivity in mice, induced by IFN-gamma producing $\mathrm{CD} 4(+)$ and $\mathrm{CD} 8(+)$ lung T cells, is responsive to steroid treatment. Scand. J. Immunol. 80, 327-338 (2014).

47. Pandolfi, P. P. et al. Targeted disruption of the GATA3 gene causes severe abnormalities in the nervous system and in fetal liver haematopoiesis. Nat. Genet. 11, 40-44 (1995).

48. Honda, A. et al. Generation of induced pluripotent stem cells in rabbits: potential experimental models for human regenerative medicine. J. Biol. Chem. 285, 31362-31369 (2010).

49. Kimura, M. et al. Regulation of Th2 cell differentiation by mel-18, a mammalian polycomb group gene. Immunity 15, 275-287 (2001).

\section{Acknowledgements}

We thank Kaoru Sugaya, Hikari Kato, Mizuho Oda, Emiko Koba, Yuki Matsuzaki and Toshihiro Ito for their expert technical assistance. We also thank C.J. Okumura and Toshi Maruyama for their fruitful discussion on the biochemical results and Yuka Masshardt for editing the manuscript. This work was supported by Grants-in-Aid for Scientific Research (S) \#26221305, (C) \#24592083, \#26460569, Exploratory Research and Young Scientists (B) \# 24790461 and \#23790522, the Takeda Science Foundation, the Astellas Foundation for Research on Metabolic Disorders, the Uehara Memorial
Foundation, the Manpei Suzuki Diabetes Foundation and Kanae Foundation for the Promotion of Medical Science. This work was partly performed in the Cooperative Research Project Program of the Medical Institute of Bioregulation, Kyushu University and also supported by Extramural Collaborative Research Grant of Cancer Research Institute, Kanazawa University.

\section{Author contributions}

H.H. designed and performed experiments, analysed data and wrote the manuscript; Y.E., M.K., K.S., A.S., S.M., M.M. and K.I.N. performed experiments and analysed data T.T. designed experiments and edited the manuscript; and T.N. conceptualized the research, directed the study and edited the manuscript.

\section{Additional information}

Supplementary Information accompanies this paper at http://www.nature.com/ naturecommunications

Competing financial interests: The authors declare no competing financial interests.

Reprints and permission information is available online at http://npg.nature.com/ reprintsandpermissions/

How to cite this article: Hosokawa, H. et al. Akt1-mediated Gata3 phosphorylation controls the repression of IFN $\gamma$ in memory-type Th2 cells. Nat. Commun. 7:11289 doi: $10.1038 /$ ncomms11289 (2016)

(c) (i) This work is licensed under a Creative Commons Attribution 4.0 International License. The images or other third party material in this article are included in the article's Creative Commons license, unless indicated otherwise in the credit line; if the material is not included under the Creative Commons license, users will need to obtain permission from the license holder to reproduce the material. To view a copy of this license, visit http://creativecommons.org/licenses/by/4.0/ 